\title{
Relationship between the physical environment and different domains of physical activity in European adults: a systematic review
}

Veerle Van Holle ${ }^{1 *}$, Benedicte Deforche ${ }^{1,2}$, Jelle Van Cauwenberg ${ }^{2}$, Liesbet Goubert ${ }^{3}$, Lea Maes ${ }^{4}$, Nico Van de Weghe ${ }^{5}$ and Ilse De Bourdeaudhuij ${ }^{1}$

\begin{abstract}
Background: In the past decade, various reviews described the relationship between the physical environment and different physical activity (PA) domains. Yet, the majority of the current review evidence relies on North American/Australian studies, while only a small proportion of findings refer to European studies. Given some clear environmental differences across continents, this raises questions about the applicability of those results in European settings. This systematic review aimed at summarizing Europe-specific evidence on the relationship between the physical environment and different PA domains in adults.

Methods: Seventy eligible papers were identified through systematic searches across six electronic databases. Included papers were observational studies assessing the relationship between several aspects of the physical environment and PA in European adults (18-65y). Summary scores were calculated to express the strength of the relationship between each environmental factor and different PA domains.

Results: Convincing evidence on positive relationships with several PA domains was found for following environmental factors: walkability, access to shops/services/work and the composite factor environmental quality. Convincing evidence considering urbanization degree showed contradictory results, dependent on the observed PA domain. Transportation PA was more frequently related to the physical environment than recreational PA. Possible evidence for a positive relationship with transportation PA emerged for walking/cycling facilities, while a negative relationship was found for hilliness. Some environmental factors, such as access to recreational facilities, aesthetics, traffic- and crime-related safety were unrelated to different PA domains in Europe.
\end{abstract}

Conclusions: Generally, findings from this review of European studies are in accordance with results from North American/Australian reviews and may contribute to a generalization of the relationship between the physical environment and PA. Nevertheless, the lack of associations found regarding access to recreational facilities, aesthetics and different forms of safety are likely to be Europe-specific findings and need to be considered when appropriate interventions are developed. More research assessing domain-specific relationships with several understudied environmental attributes (e.g., residential density) is needed.

Keywords: Domain-specific physical activity, Built environment, Continent-specific, Transportation

\footnotetext{
* Correspondence: Veerle.VanHolle@UGent.be

'Department of Movement and Sports Sciences, Ghent University, Watersportlaan 2, B-9000 Ghent, Belgium

Full list of author information is available at the end of the article
} 


\section{Background}

Regular moderate-to-vigorous intensity physical activity (MVPA) contributes to several beneficial short- and long term health effects [1-3]. Unfortunately, about 31 percent ( $28 \%$ men, $34 \%$ women) of the global adult population is inadequately active to achieve health benefits [4]. To promote physical activity (PA) in the adult population, research investigating its possible underlying determinants and correlates is essential. While earlier research on this topic focused mainly on the contribution of personal determinants of PA behavior, social ecological models have been of growing interest during the last decade. These models put forward that domainspecific PA is influenced by multiple factors, which interact across different levels [5-7]. Of particular interest is the environmental level, including the physical environment. Davison and Lawson defined the physical environment as the objective and perceived characteristics of the physical context in which people spend their time (e.g., home, neighborhood), including aspects of urban design (e.g., presence of sidewalks), traffic density and speed, distance to and design of venues for PA (e.g., parks), crime and safety [8]. As physical environmental attributes are changeable and such changes can influence health-related behaviors such as PA, insight into physical environmental correlates of PA is crucial when developing interventions to promote PA.

At present, several reviews have summarized the available evidence on the relationship between the physical environment and different PA domains in adult populations [9-16]. Remarkably, the majority of discussed studies in these reviews were carried out in North American and Australian settings, while the proportion of studies conducted in other continents like Europe are more limited. Moreover, none of these reviews provided separate results for different geographical regions. Currently, it is not clear yet whether the results on environmental correlates of PA found in America or Australia are applicable to European countries, so further research is needed before transferring findings across continents. Since research on environmental correlates of food-intake shows that associations may well differ between countries [17], it is plausible that this is also true for environmental correlates of PA. Moreover, physical environmental attributes in Europe are likely to differ from an American or Australian context. For example, European urban streetscapes are characterized by a more compact structure, whereas most American cities are less dense due to suburbanization and existence of peripheral centers [18]. Because of these dissimilarities in density, average trip distances in Europe are shorter than in the US $[19,20]$, which in turn can influence human behavior like active versus passive transport mode choices. Bassett and colleagues strengthen the assumption that also the behavior itself can be a continent-specific phenomenon, by showing that active transportation trips are much more common in Europe when compared to North America and Australia [21]. In addition to the above-mentioned geographical and behavioral differences, there has been a recent boost in European studies investigating physical environmental correlates of PA in adult populations, making it relevant to update the existing European literature on this topic.

In summary, there is uncertainty about the applicability of North American and Australian results on the relationship between the physical environment and adults' PA in European settings. Additionally, European research in this field is growing and therefore, this systematic review aims to provide an overview of the available European evidence during the last decade. As PA can be subdivided into several domains (e.g., transportation, recreation) and particular environmental attributes may relate differently to specific PA domains [12,22], relationships between several physical environmental factors and specific PA domains will be investigated.

\section{Methods}

\section{Search strategy}

Systematic searches were conducted across six electronic databases: Cinahl, Cochrane, PubMed, SportDiscus, TRIS and Web of Science. A two-stage search was conducted to identify eligible studies published between January 2000 and August 2011. In a first stage, the third author (JVC) screened databases until January 2010. In the second stage, an update of electronic database screening was conducted by the first author (VVH), who also performed all subsequent screening steps. Figure 1 provides an overview of the search protocol, according to the PRISMA statement [23] and specifies the used search terms. After excluding duplicates and making exclusions based on title and abstract, 73 papers remained. Twenty of these studies were excluded based on full text. Backward screening of the remaining 53 papers' reference lists and forward screening of citations yielded 17 more papers, resulting in a total amount of 70 eligible papers [24-93] for this review. During the entire screening process, eligibility of doubtful publications was discussed with the second author (BD) until consensus was reached.

\section{Eligibility criteria}

During database screening, following inclusion criteria were applied: suitable papers were restricted to Englishwritten observational studies on European adult samples (mean age of the study population between 18 and 65y, or - in case no mean age was provided - an age range restriction from 18-65y). Eligible publications had to be cross-sectional or longitudinal studies, investigating the 


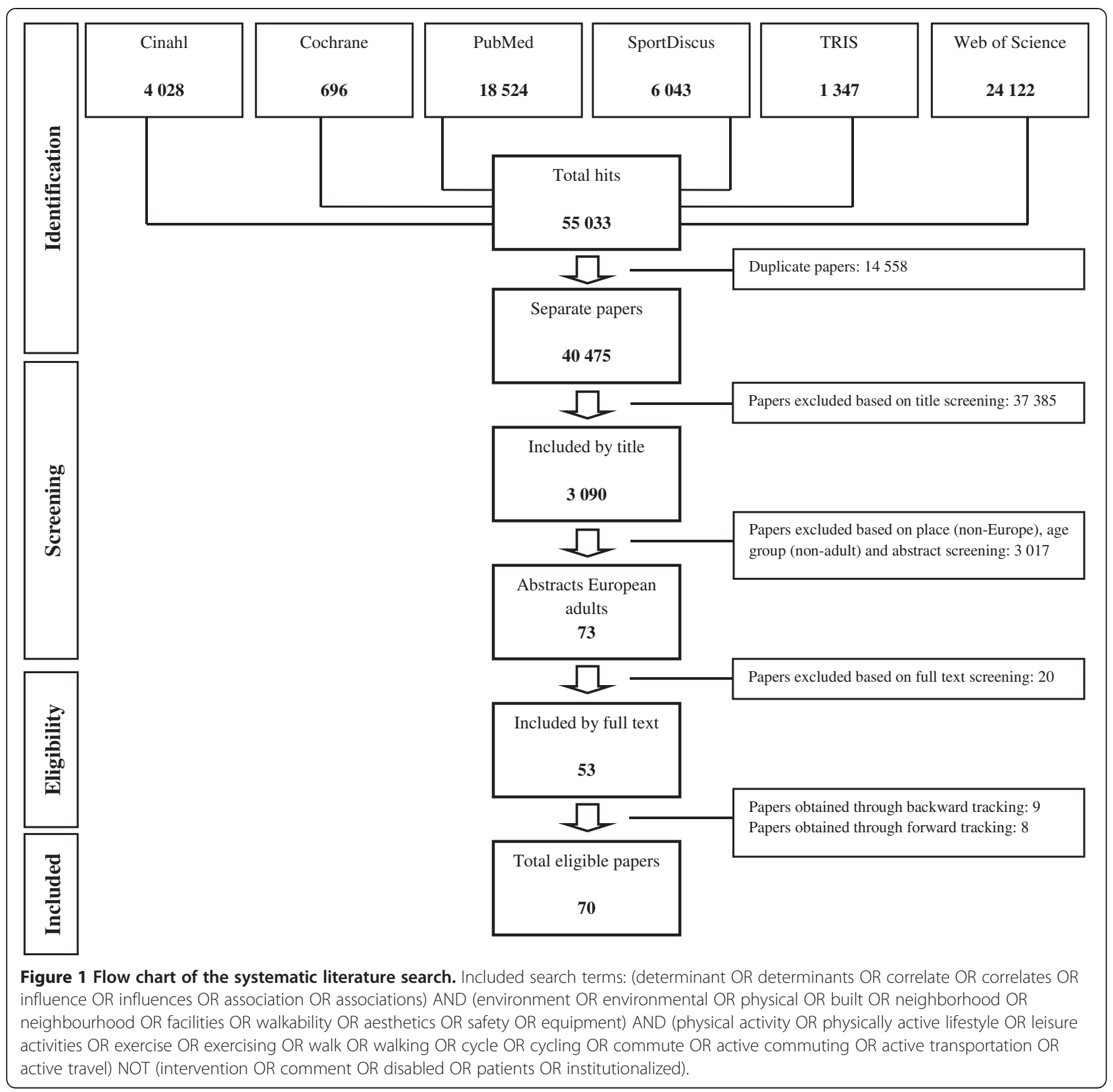

relationship between objective or subjective measures of PA and the physical environment. Exclusion criteria were set as follows: studies describing exclusively nonEuropean samples and/or populations outside the specified age range were not eligible. Papers were also excluded when they considered exclusively physical environmental measures, or PA, respectively. Furthermore, studies focusing only on occupational and/or household PA as dependent variable were excluded, since these behaviors are bounded to very specific contexts (i.e., the workplace and home residence) and, consequently, are less susceptible to changes in physical environmental attributes of the residential neighborhood. Concerning the independent variable, studies that only focused on the socio-cultural, economic or policy environment were excluded. From a study design perspective, qualitative reports, interventions, experiments, case studies and experts' opinions were not eligible. At last, studies focusing on disabled, unhealthy, overweight, obese or pregnant participants were excluded.

\section{Selection of the variables}

Included dependent variables were measures of 1) total PA, 2) leisure-time PA (LTPA), 3) total walking and/or cycling, 4) recreational walking and/or cycling, 5) active transportation in general, 6) transportation 
walking and 7) transportation cycling. Physical environmental characteristics were classified according to the categories applied in the valid and reliable Neighborhood Environment Walkability Scale (NEWS questionnaire, [94-96]), which is the most internationally used questionnaire to assess perceptions of the environmental correlates of PA $[97,98]$. Retained independent variables were 1) walkability and its three key elements: 2) residential density, 3) land use mix diversity, and 4) street connectivity. Further included independent variables were 5) access to shops/services/workplace, 6) access to public transport, 7) access to recreational facilities, including greenery and places or facilities for PA, 8) quality and presence of walking and cycling facilities, 9) general safety, 10) traffic safety, 11) safety from crime and 12) aesthetic features. In addition to the NEWS categories, three other environmental attributes were included as independent variables. As worldwide studies already revealed that urban-rural differences are associated with variations in PA [99], "degree of urbanization" was added as a $13^{\text {th }}$ variable, often expressed as a measure of a region's population density or the size of the municipality. Throughout the screening process, the $14^{\text {th }}$ variable "hilliness" and $15^{\text {th }}$ variable "quality of the environment", a composite environmental measure assessing general activity-friendliness, were identified as important variables in the research domain. Studies were included if they provided results on relationships between at least one of the above-mentioned dependent and at least one of the independent variables.

\section{Data extraction}

Next, data extraction tables were constructed for each separate PA category mentioned above. Study results were coded as significant positive "+", significant negative "-", or insignificant " 0 " relationships. If both univariate and multivariate results were provided, the univariate results were considered, in order to keep comparability between different studies as high as possible. For the same reason and when available, study results controlling for the least variables were retained [100]. When analyses were conducted separately for male and female participants, respectively "M" or " $\mathrm{F}$ " was indicated in superscript. If analyses were conducted for different subgroups in a study (e.g. low vs high SES or separate countries in a multicountry study), superscript numbers were added. If analyses were done for different time periods, superscripts "I" and "II" were added. Finally, as outcomes based upon objective and perceived measurements of both PA [101] and the physical environment [102] can differ, a distinction was made between these measurement methods: regular font was used when both PA and the physical environment were measured subjectively. Objective measures of PA and the physical environment were indicated by using italics and bold font, respectively. A more detailed description of all measures per individual study is accessible in "Additional file 1".

\section{Coding of the evidence}

Further classification of the evidence was based upon criteria provided in the review of Wendel-Vos and colleagues [14]. In specific, the number of times an environmental factor was significantly related to a PA domain was divided by the total amount of records on this relationship. When associations in one direction were found in more than $50 \%$ of all records, this was regarded as convincing evidence, summary coded "+" for a positive association and "_" for a negative. However, in case simultaneously at least $25 \%$ of all records reported results in the opposite direction, this was regarded as only possible evidence, summary coded "(+)" or "(-)" for a possible positive or negative association, respectively. Summary codes for possible evidence were also applied if an association was found in $40-50 \%$ of all records. Associations found in less than $40 \%$ of all records, or in $40-50 \%$ of all records in one direction with at least $25 \%$ in the opposite, was regarded as no evidence, summary coded " 0 ". Double signed summary codes were applied when convincing positive "++", convincing negative "--", possible positive " $(++)$ ", possible negative "(--)" or no "00" associations were present in at least four independent samples, and this was regarded as strong evidence. Yet, all aforementioned coding only counted when a relationship was investigated in at least three independent samples, otherwise evidence was considered as not applicable, coded "N/A". An overview of the summary coding is provided in Table 1.

Table 1 Criteria for summary coding of the evidence

\begin{tabular}{lcc}
\hline Percentages of records supporting association ${ }^{\mathbf{1}}$ & ${\text { Summary } \text { code }^{\mathbf{2}}}^{c}$ & Description \\
\hline $0-39 \%$ associated & 0 & Evidence unrelated \\
\hline $40-50 \%$ associated in one direction and $\geq 25 \%$ in the opposite & Evidence unrelated \\
\hline $40-50 \%$ associated in one direction and $<25 \%$ in the opposite & $(+) ;(-)$ & Possible evidence for a positive/negative relationship \\
\hline $51-100 \%$ associated in one direction and $\geq 25 \%$ in the opposite & $(+) ;(-)$ & Possible evidence for a positive/negative relationship \\
\hline $51-100 \%$ associated in one direction and $<25 \%$ in the opposite & $+;-$ & Convincing evidence for a positive/negative relationship
\end{tabular}

${ }^{1}$ Only valid when relationship was investigated in at least three independent samples, otherwise evidence was regarded "not applicable" (coded N/A).

2 Double signed summary codes are applied when convincing positive "++", convincing negative "-", possible positive "(++)", possible negative "(--)" or no "00" associations were present in at least four independent samples. 


\section{Results}

\section{Study characteristics}

Across the 70 retained papers, data gathered in 66 unique samples across 27 European countries was available. As depicted in Table 2, the largest part of studies were conducted in the United Kingdom, Belgium and The Netherlands, respectively covering 19, 16 and 13 publications. Twenty-one studies calculated split results for men and women and four studies analyzed data for separate subgroups. Only one study [43] provided longitudinal data. Regarding PA measurement methods, six studies used objective data, compared to 59 studies using subjective data. Another five studies used both objective and subjective PA measurement methods. For environmental measurement methods, the distribution was more balanced: 31 studies used only objective data, 28 studies only subjective and 11 studies combined both. Total PA was the most studied PA variable, measured in 34 studies, while total cycling was the least studied, with only two studies that assessed it as a separate variable.
The most studied environmental variable was access to recreation facilities, which was measured in 31 studies, and the least studied environmental variable, appearing in three studies, was hilliness. A complete overview of sample sizes, mean ages, study designs and measurement methods is shown in Table 3.

\section{Physical environment and the relationship with total physical activity}

Thirty-four studies assessed relationships between aspects of the physical environment and measures of total PA. Summary results considering this relationship are depicted in Table 4. Convincing evidence for a positive relationship with total PA was found for the factors walkability and quality of the environment, with a strong relationship for walkability (results of at least four independent samples underpin the relationship). For urbanization degree, there was convincing evidence for a negative relationship, which means that people living in less urbanized areas tended to be more physically active.

Table 2 Overview of the European countries' distribution across studies

\begin{tabular}{|c|c|c|}
\hline Country & Reference number & Total \\
\hline Bosnia-Herzegovina & $45^{*}$ & 1 \\
\hline Estonia & $45^{*}$ & 1 \\
\hline Georgia & $45^{*}$ & 1 \\
\hline Ireland & $69^{*}$ & 1 \\
\hline Luxembourg & $69^{*}$ & 1 \\
\hline Poland & 51 & 1 \\
\hline Turkey & $45^{*}$ & 1 \\
\hline Ukraine & $45^{*}$ & 1 \\
\hline Croatia & $45^{*}, 56$ & 2 \\
\hline Denmark & $69 *, 81$ & 2 \\
\hline$\underline{\text { Greece }}$ & $66,69^{*}$ & 2 \\
\hline Lithuania & $37^{*}, 55^{*}, 73^{*}$ & 3 \\
\hline Austria & $69 *, 77,79,80$ & 4 \\
\hline Czech Republic & $36,42,45^{*}, 74$ & 4 \\
\hline Hungary & $37^{*}, 45^{*}, 55^{*}, 73^{*}$ & 4 \\
\hline Slovakia & $37^{*}, 45^{*}, 55^{*}, 73^{*}$ & 4 \\
\hline Finland & $24^{*}, 37^{*}, 68^{*}, 69^{*}, 76^{*}$ & 5 \\
\hline Switzerland & $37^{*}, 55^{*}, 68^{*}, 73^{*}, 76^{*}$ & 5 \\
\hline France & $24^{*}, 27,55^{*}, 69^{*}, 73^{*}$ & 5 \\
\hline Italy & $24^{*}, 30,55^{*}, 69^{*}, 73^{*}$ & 5 \\
\hline Sweden & $25,26,28,44,69^{*}, 78$ & 6 \\
\hline Germany & $24^{*}, 37^{*}, 55^{*}, 68^{*}, 69^{*}, 73^{*}, 76^{*}$ & 7 \\
\hline Portugal & $37^{*}, 55^{*}, 69^{*}, 70,71,72,73^{*}$ & 7 \\
\hline Spain & $24^{*}, 29,45^{*}, 57,65,68^{*}, 69^{*}, 76^{*}$ & 8 \\
\hline The Netherlands & $24^{*}, 38,43,49,50,52,53,68^{*}, 69^{*}, 76^{*}, 88,92,93$ & 13 \\
\hline Belgium & $33,34,35,59,68^{*}, 69^{*}, 76^{*}, 82,83,84,85,86,87,89,90,91$ & 16 \\
\hline UK & $24^{*}, 31,32,39,40,41,46,47,48,54,58,60,61,62,63,64,66,69^{*}, 75$ & 19 \\
\hline
\end{tabular}

*Country was involved as part of a multi-country study. 
Table 3 Categorization of samples by size, mean age, design, environmental and physical activity variables Reference number

\section{Sample size}

\begin{tabular}{|c|c|c|}
\hline$<100$ & 36 & \\
\hline $100-199$ & $44^{1}, 82$ & \\
\hline $200-299$ & $33^{\mathrm{M}}, 33^{\mathrm{F}}, 34^{1}, 34^{2}, 74^{\mathrm{M}}$ & \\
\hline $300-499$ & $35,44^{2}, 59,60,61,69^{14}, 74^{\mathrm{F}}, 77^{\mathrm{M}}, 84,86$ & 10 \\
\hline $500-999$ & $31,38,53^{\mathrm{M}}, 53^{\mathrm{F}}, 55^{\mathrm{M}}, 57,62^{\mathrm{M}}, 62^{\mathrm{F}}, 69^{12}, 77^{\mathrm{F}}, 79,80$ & 12 \\
\hline $1000-2999$ & $\begin{array}{l}25,26,30,39^{\mathrm{M}}, 39^{\mathrm{F}}, 55^{\mathrm{F}}, 58,68^{\mathrm{M}}, 68^{\mathrm{F}}, 69^{1}, 69^{2}, 69^{3}, 69^{4}, 69^{5}, 69^{6}, 69^{7}, 69^{8}, 69^{9}, 69^{10}, 69^{11}, 69^{12}, \\
69^{13}, 69^{15^{12}}, 69^{16}, 69^{17}, 73^{\mathrm{M}}, 73^{\mathrm{F}}, 78,83,85,93\end{array}$ & 31 \\
\hline $3000-4999$ & $24,27^{\mathrm{M}}, 27^{\mathrm{F}}, 39,42^{\mathrm{M}}, 47,49,51^{\mathrm{M}}, 51^{\mathrm{F}}, 52,56^{\mathrm{M}}, 56^{\mathrm{F}}, 66,71^{\mathrm{M}}, 71^{\mathrm{F}}, 72^{\mathrm{M}}, 72^{\mathrm{F}}, 76,87,88^{1}, 88^{2}$ & 21 \\
\hline $5000-9999$ & $29^{\mathrm{M}}, 29^{\mathrm{F}}, 32,37,40^{\mathrm{M}}, 40^{\mathrm{F}}, 41^{\mathrm{M}}, 41^{\mathrm{F}}, 42^{\mathrm{F}}, 43^{\mathrm{MI}}, 43^{\mathrm{MII}}, 43^{\mathrm{FI}}, 43^{\mathrm{FII}}, 48,54,64,70,73,75$ & 19 \\
\hline$\geq 10000$ & $28,45^{\mathrm{M}}, 45^{\mathrm{F}}, 46,50,63,65^{\mathrm{M}}, 65^{\mathrm{F}}, 67,81,89,90,91,92$ & 14 \\
\hline \multicolumn{3}{|l|}{ Mean age (years) } \\
\hline $18.0-29.9$ & 57,79 & 2 \\
\hline $30.0-39.9$ & $34,36,51,71,72,74,75,77,80,90,91$ & 11 \\
\hline $40.0-49.9$ & $\begin{array}{l}24,25,26,28,29,33,35,38,39,42,44,45,46,49,52,53,55,58,59,65,66,67,68,73,76,78,81 \\
82,83,84,85,86,87,88,89,93\end{array}$ & 36 \\
\hline $50.0-59.9$ & $27,32,48,60,61$ & 5 \\
\hline $60.0-64.9$ & $40,41,47,62$ & 4 \\
\hline only provision of age range & $30,31,37,43,50,54,56,63,64,69,70,93$ & 12 \\
\hline \multicolumn{3}{|l|}{ Study design } \\
\hline Cross-sectional & $\begin{array}{l}24,25,26,27,28,29,30,31,32,33,34,35,36,37,38,39,40,41,42,44,45,46,47,48,49,50,51, \\
52,53,54,55,56,57,58,59,60,61,62,63,64,65,66,67,68,69,70,71,72,73,74,75,76,77,78, \\
79,80,81,82,83,84,85,86,87,88,89,90,91,92,93\end{array}$ & 69 \\
\hline Longitudinal & 43 & 1 \\
\hline \multicolumn{3}{|l|}{ Measurement environment } \\
\hline Objective & $\begin{array}{l}27,28,30,32,36,37,40,41,43,45,47,51,52,53,56,65,66,70,78,79,80,82,83,84,86,87,88, \\
89,90,91,92\end{array}$ & 31 \\
\hline Subjective & $24,25,26,33,34,35,38,39,42,44,46,49,50,59,60,63,67,68,69,71,72,73,74,75,76,77,85,93$ & 28 \\
\hline Both & $29,31,48,54,55,57,58,61,62,64,81$ & 11 \\
\hline \multicolumn{3}{|l|}{ Measurement PA } \\
\hline Objective & $36,64,74,75,90,91$ & 6 \\
\hline Subjective & $\begin{array}{l}24,25,26,27,28,29,30,31,32,33,34,35,37,38,40,39,41,42,43,44,45,46,47,48,49,50,51, \\
52,53,54,55,56,57,58,59,60,61,62,63,65,66,67,68,69,70,71,72,73,76,77,78,79,80,81 \\
87,88,89,92,93\end{array}$ & 59 \\
\hline Both & $82,83,84,85,86$ & 5 \\
\hline \multicolumn{3}{|l|}{ Environmental variables } \\
\hline Walkability & $36,59,61,78,82,83,85,86,87$ & 9 \\
\hline Residential density & $32,33,34,53,55,87$ & 6 \\
\hline$\underline{\text { Land use mix diversity }}$ & $32,33,34,62,80$ & 5 \\
\hline Street connectivity & $32,33,34,62,85$ & 5 \\
\hline Access to shops/services/work & $31,33,34,35,38,39,46,53,54,57,58,62,63,64,67,70,74,77,85,88,90,91$ & 22 \\
\hline Access to public transport & $33,34,35,46,50,53,57,93$ & 8 \\
\hline Access to recr. facilities & $\begin{array}{l}24,28,29,30,32,33,34,40,39,44,46,47,48,49,52,54,58,60,61,62,65,67,68,69,70,73,74 \\
76,81,85,91,92\end{array}$ & 32 \\
\hline Walking/cycling facilities & $26,33,34,35,57,58,62,64,74,80,85,90,91$ & 13 \\
\hline Safety & $39,46,48,49,54,55,63,71,72,73,74,80,85$ & 13 \\
\hline Traffic-related safety & $26,31,32,33,34,35,40,39,41,46,55,58,62,64,70,79,80,85,90,91$ & 20 \\
\hline Crime-related safety & $26,31,33,34,35,40,46,49,58,62,63,67,70,75,79,85,88,90,91$ & 19 \\
\hline Aesthetics & $29,31,33,34,69,39,49,54,55,58,63,73,74,79,80,85,88,91$ & 18 \\
\hline
\end{tabular}


Table 3 Categorization of samples by size, mean age, design, environmental and physical activity variables (Continued)

\begin{tabular}{|c|c|c|}
\hline Hilliness & $64,80,91$ & 3 \\
\hline Urbanization & $25,26,27,29,35,42,43,45,51,54,56,62,64,66,67,70,81,84,89,90,91$ & 21 \\
\hline Quality of the environment & $29,54,61,71,72,74,77$ & 7 \\
\hline \multicolumn{3}{|l|}{ PA variables } \\
\hline Total PA & $\begin{array}{l}24,25,26,28,30,31,32,33,34,36,37,42,44,45,46,48,52,56,57,58,61,67,68,69,72,74,76,78, \\
82,83,84,85,86,87\end{array}$ & 34 \\
\hline$\underline{\text { Leisure-time PA (LTPA) }}$ & $27,29,34,40,42,43,47,49,52,55,60,61,65,66,67,70,70,73,75,77,81,84,85,86,88,89$ & 26 \\
\hline Total walking & $26,33,39,42,54,61,67,71,92,93$ & 10 \\
\hline Total cycling & 92,93 & 2 \\
\hline Recreational walking & $34,40,52,63,78,82,83,84,85,86,92$ & 11 \\
\hline Recreational cycling & $40,41,52,82,84,92$ & 6 \\
\hline Active transportation & $34,51,57,58,62,88$ & 6 \\
\hline Walking for transportation & $50,52,63,77,78,82,83,84,85,86,92$ & 11 \\
\hline Cycling for transportation & $35,38,41,50,52,53,59,64,77,79,80,82,83,84,85,86,90,91,92$ & 19 \\
\hline
\end{tabular}

$\mathrm{M}=$ male subgroup; $\mathrm{F}=$ female subgroup; $\mathrm{I}=$ subgroup 1 st measurement period; $\mathrm{II}=$ subgroup 2 nd measurement period; superscript numbers indicate subgroups based on other classification criteria (e.g., country).

Further, possible evidence for a positive relationship emerged between total PA and access to recreation facilities. All other environmental factors were unrelated to total PA.
Physical environment and the relationship with leisuretime physical activity

The relationship between the physical environment and LTPA was examined in 26 studies, of which summary

Table 4 Summary results of evidence on the relationship environmental factors and total PA

\begin{tabular}{|c|c|c|c|c|c|c|c|}
\hline Environm. variables & Positive association & $\begin{array}{l}\text { Negative } \\
\text { association }\end{array}$ & No association & $A^{*}$ & $\mathrm{~B}^{*}$ & $C^{*}$ & $D^{*}$ \\
\hline Walkability & $36,61,78,82,82^{2}, 83,85,86,87$ & & $82^{1}$ & 8 & $9 / 10$ & 90 & ++ \\
\hline Residential density & 87 & & $32,33^{\mathrm{M}}, 33^{\mathrm{M}}, 33^{\mathrm{F}}, 33^{\mathrm{F}}, 34,34$ & 4 & $1 / 8$ & 13 & 0 \\
\hline Land use mix diversity & 34 & & $32,33^{\mathrm{M}}, 33^{\mathrm{M}}, 33^{\mathrm{F}}, 33^{\mathrm{F}}, 34$ & 3 & $1 / 7$ & 14 & 0 \\
\hline Street connectivity & $32,32,32$ & & $33^{\mathrm{M}}, 33^{\mathrm{M}}, 33^{\mathrm{F}}, 33^{\mathrm{F}}, 34,34,85$ & 4 & $3 / 10$ & 30 & 0 \\
\hline $\begin{array}{l}\text { Access to shops/ } \\
\text { services/work }\end{array}$ & $31,31,31,31,31,33^{\mathrm{F}}, 67,74^{\mathrm{F}}$ & 8 & $\begin{array}{l}33^{\mathrm{M}}, 33^{\mathrm{M}}, 33^{\mathrm{F}}, 34,34,46, \mathbf{5 7}, \mathbf{5 8} \\
58,58,67,74^{M}, 74^{M}, 74^{F}, 82,82,85\end{array}$ & 9 & $8 / 26$ & 31 & 00 \\
\hline $\begin{array}{l}\text { Access to public } \\
\text { transport }\end{array}$ & & & $33^{\mathrm{M}}, 33^{\mathrm{M}}, 33^{\mathrm{F}}, 33^{\mathrm{F}}, 34,34,46,57$ & 4 & $0 / 8$ & 0 & 00 \\
\hline $\begin{array}{l}\text { Access to recreation } \\
\text { facilities }\end{array}$ & $\begin{array}{l}24, \mathbf{2 8}, \mathbf{2 8}, \mathbf{3 0}, \mathbf{3 0} 33^{\mathrm{M}}, 33^{\mathrm{F}}, 44^{1}, 44^{2}, 46 \\
48^{1}, 48^{2}, 61,67,68^{\mathrm{M}}, 68^{\mathrm{F}}, 69^{1}, 69^{2}, 69^{3}, \\
69^{4^{1}} 69^{5}, 69^{6}, 69^{7}, 69^{9}, 69^{10}, 69^{11}, 69^{12} \\
69^{14}, 69^{15}, 69^{16}, 76\end{array}$ & & 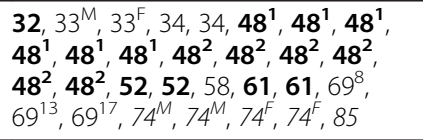 & 17 & $31 / 61$ & 51 & $\overline{(++)}$ \\
\hline $\begin{array}{l}\text { Walking/cycling } \\
\text { facilities }\end{array}$ & 26 & & $\begin{array}{l}26,33^{M}, 33^{M}, 33^{M}, 33^{M}, 33^{F}, 33^{F} \\
33^{F}, 33^{F}, 34,34,34,34,57,58 \\
74^{M}, 74^{F}, 85,85\end{array}$ & 7 & $1 / 20$ & 5 & 00 \\
\hline Safety & $46,46,48^{1}, 48^{2}$ & & $72^{\mathrm{M}}, 72^{\mathrm{M}}, 72^{\mathrm{F}}, 72^{\mathrm{F}}, 74^{\mathrm{M}}, 74^{\mathrm{F}}, 85$ & 6 & $4 / 11$ & 36 & 0 \\
\hline Traffic-related safety & $26, \mathbf{3 1}, \mathbf{3 1}$ & $32, \mathbf{3 2}, 46,58$ & $\begin{array}{l}26,33^{\mathrm{M}}, 33^{\mathrm{M}}, 33^{\mathrm{F}}, 33^{\mathrm{F}}, 34,34,46, \\
58,85\end{array}$ & 7 & $4 / 17$ & 24 & 00 \\
\hline Crime-related safety & 26,31 & 46,67 & $\begin{array}{l}26,33^{\mathrm{M}}, 33^{\mathrm{M}}, 33^{\mathrm{F}}, 33^{\mathrm{F}}, 34,34,46, \\
46,58,67,85\end{array}$ & 7 & $2 / 16$ & 13 & 00 \\
\hline Aesthetics & $31, \mathbf{3 7}, \mathbf{3 7}, 74^{M}$ & & $33^{\mathrm{M}}, 33^{\mathrm{M}}, 33^{\mathrm{F}}, 33^{\mathrm{F}}, 34,34,58,74^{\mathrm{F}}, 85$ & 7 & $4 / 13$ & 31 & 00 \\
\hline Urbanization & & $\begin{array}{l}25,26,42^{M}, 42^{M} \\
42^{F}, 42^{F} \mathbf{4 5}^{M}, 45^{F} \\
\mathbf{5 6}^{M}, \mathbf{5 6}^{\mathrm{F}}\end{array}$ & $25,26,67,84$ & 7 & $10 / 14$ & 71 & - \\
\hline Quality of environment & $61,72^{\mathrm{F}}, 72^{\mathrm{F}}, 74^{M}, 74^{\mathrm{F}}$ & & $72^{M}, 72^{M}$ & 3 & $5 / 7$ & 71 & + \\
\hline
\end{tabular}

${ }^{*} \mathrm{~A}=\mathrm{n}^{\circ}$ of independent studies; $\mathrm{B}=\mathrm{n}^{\circ}$ of associated records divided by all records; $\mathrm{C}=\%$ of evidence; $\mathrm{D}=$ summary code.

Regular vs italics font = subjective vs objective PA measures; regular vs bold font = subjective vs objective environmental measures.

$\mathrm{M}=$ specific results for males; ${ }^{\mathrm{F}}=$ specific results for females; ${ }^{1}=$ specific results for $1^{\text {st }}$ subgroup; ${ }^{2}=$ specific results for $2^{\text {nd }}$ subgroup; ${ }^{\mathrm{n}}=$ specific results for $\mathrm{n}^{\text {th }}$ subgroup. 
results are presented in Table 5 . There was only possible evidence for a positive relationship between LTPA and quality of the environment, whereas the factors walkability, access to shops/services/work, access to recreation facilities, general safety, traffic- and crime-related safety, aesthetics and urbanization were all unrelated to LTPA. Summary results could not be calculated for the three separate components of walkability, access to public transport and walking/cycling facilities because too few studies investigated the relationship of these environmental factors with LTPA.

\section{Physical environment and the relationship with total walking and cycling}

Summary results for the studies investigating the relationship between physical environmental factors and total walking and cycling are shown in Table 6. Out of the 10 studies, eight $[26,33,39,42,54,61,67,71]$ studied only walking and two $[92,93]$ studied both walking and cycling as separate variables. Possible evidence for a positive relationship was found between urbanization degree and total walking, which means that people living in more urbanized areas possibly walked more than people living in less urbanized regions. Summary calculations resulted in no association of total walking and cycling with access to shops/services/work, access to recreation facilities, general safety, traffic- and crime-related safety and aesthetics. Study results were not applicable for the relationship between the remaining physical environmental factors and total walking and cycling due to a lack of sufficient individual studies in these categories.

\section{Physical environment and the relationship with recreational walking and cycling}

Twelve studies, presented in Table 7, assessed relationships between the physical environment and recreational walking and cycling. Six studies $[34,63,78,83,85,86]$ investigated only walking, one study [41] focused on only cycling and five studies [40,52,82,84,92] measured both. Convincing evidence for a positive relationship with recreational walking and cycling emerged for traffic-related safety, which means that people living in less trafficked (and thus potentially safer) areas walked or cycled more for recreation. Further, evidence showed no association of recreational walking and cycling with walkability, access to shops/services/work, access to recreation facilities, crime-related safety and aesthetics. Results considering the remaining factors were not applicable due to a lack of sufficient studies in each category.

Table 5 Summary results of evidence on the relationship environmental factors and leisure-time PA (LTPA)

\begin{tabular}{|c|c|c|c|c|c|c|c|}
\hline Environm. variables & Positive association & $\begin{array}{l}\text { Negative } \\
\text { association }\end{array}$ & No association & $A^{*}$ & $\mathrm{~B}^{*}$ & $C^{*}$ & $\mathrm{D}^{*}$ \\
\hline Walkability & 61 & & $85,85,86$ & 3 & $1 / 4$ & 25 & 0 \\
\hline Residential density & & & 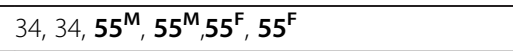 & 2 & N/A & N/A & $\mathrm{N} / \mathrm{A}$ \\
\hline Land use mix diversity & 34 & & 34 & 1 & $\mathrm{~N} / \mathrm{A}$ & $\mathrm{N} / \mathrm{A}$ & $\mathrm{N} / \mathrm{A}$ \\
\hline Street connectivity & & & $34,34,85,85$ & 2 & $\mathrm{~N} / \mathrm{A}$ & $\mathrm{N} / \mathrm{A}$ & $\mathrm{N} / \mathrm{A}$ \\
\hline $\begin{array}{l}\text { Access to shops/ } \\
\text { services/work }\end{array}$ & 70,88 & & $34,34,67,67,70,70,70,77,77,85,85$ & 5 & $2 / 13$ & 15 & 00 \\
\hline $\begin{array}{l}\text { Access to public } \\
\text { transport }\end{array}$ & & & 34,34 & 1 & N/A & N/A & $\mathrm{N} / \mathrm{A}$ \\
\hline $\begin{array}{l}\text { Access to recreation } \\
\text { facilities }\end{array}$ & $\begin{array}{l}29^{\mathrm{M}}, 29^{\mathrm{F}}, \mathbf{4 0} \mathbf{F}^{\mathrm{F}}, \mathbf{5 2}, 60 \\
60,67, \mathbf{7 0}, 81,81,85\end{array}$ & 60,60 & 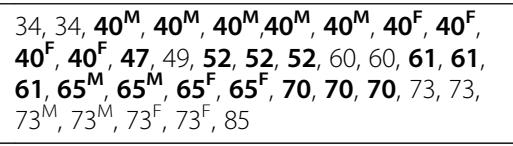 & 14 & $11 / 48$ & 23 & 00 \\
\hline Walking/cycling facilities & & & $34,34,34,34,85,85,85,85$ & 2 & $\mathrm{~N} / \mathrm{A}$ & $\mathrm{N} / \mathrm{A}$ & $\mathrm{N} / \mathrm{A}$ \\
\hline Safety & 49 & $\begin{array}{l}73,73^{\mathrm{M}} \\
73^{\mathrm{F}}, 73^{\mathrm{F}}\end{array}$ & $55^{\mathrm{M}}, 55^{\mathrm{M}}, 55^{\mathrm{F}}, 55^{\mathrm{F}}, 73,73^{\mathrm{M}}, 85,85$ & 3 & $4 / 13$ & 31 & 0 \\
\hline Traffic-related safety & & & $34,34, \mathbf{5 5}^{\mathbf{M}}, \mathbf{5 5}^{\mathbf{M}}, \mathbf{5 5}^{\mathrm{F}}, \mathbf{5 5}^{\mathrm{F}}, \mathbf{7 0}, \mathbf{7 0}, 85,85$ & 3 & $0 / 10$ & 0 & 0 \\
\hline Crime-related safety & 70,75 & & $34,34,49,67,67, \mathbf{7 0}, 85,85, \mathbf{8 8}, \mathbf{8 8}$ & 6 & $2 / 12$ & 17 & 00 \\
\hline Aesthetics & 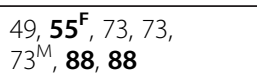 & & $\begin{array}{l}29^{\mathrm{M}}, 29^{\mathrm{M}}, 29^{\mathrm{M}}, 29^{\mathrm{M}}, 29^{\mathrm{F}}, 29^{\mathrm{F}}, 29^{\mathrm{F}}, 29^{\mathrm{F}}, 34,34, \\
\mathbf{5}^{\mathbf{M}^{\mathrm{M}},}, \mathbf{5 5}^{\mathrm{M}}, \mathbf{5 5}^{\mathrm{F}}, 73^{\mathrm{M}}, 73^{\mathrm{F}}, 73^{\mathrm{F}}, 85,85, \mathbf{8 8}\end{array}$ & 6 & $7 / 26$ & 27 & 00 \\
\hline Urbanization & $29^{M}, 40,81,89,89^{M}$ & $\begin{array}{l}27^{\mathrm{F}}, 42^{\mathrm{M}} \\
42^{\mathrm{F}}, 66\end{array}$ & $\begin{array}{l}27^{\mathrm{M}}, 29^{\mathrm{F}}, 43^{\mathrm{MI}}, 43^{\mathrm{MII}}, 43^{\mathrm{FI}}, 43^{\mathrm{FII}}, 67,70,70, \\
84,84,89,89,89,89^{\mathrm{M}}, 89^{\mathrm{M}}, 89^{\mathrm{M}}, 89^{\mathrm{F}}, 89^{\mathrm{F}}, \\
89^{\mathrm{F}}, 89^{\mathrm{F}}\end{array}$ & 10 & $5 / 30$ & 17 & 00 \\
\hline Quality of environment & $77^{\mathrm{M}}, 77^{\mathrm{F}}$ & & $29^{\mathrm{M}}, 29^{\mathrm{F}}, 61$ & 3 & $2 / 5$ & 40 & $(+)$ \\
\hline
\end{tabular}

${ }^{*} A=n^{\circ}$ of independent studies; $B=n^{\circ}$ of associated records divided by all records; $C=\%$ of evidence; $D=$ summary code.

Regular vs italics font $=$ subjective vs objective PA measures; regular vs bold font $=$ subjective vs objective environmental measures

${ }^{M}=$ specific results for males; ${ }^{F}=$ specific results for females; ${ }^{1}=$ specific results for $1^{\text {st }}$ measurement period; ${ }^{\prime \prime}=$ specific results for $2^{\text {nd }}$ measurement period 


\section{Physical environment and the relationship with general active transportation}

Six studies investigated relationships of the physical environment with general active commuting. Results of the summary calculations are depicted in Table 8. Convincing evidence for a positive relationship was found between active transportation and access to shops/services/ work and possible evidence for a positive relationship with active transportation emerged for walking/cycling facilities. Access to recreation facilities, traffic- and crimerelated safety and aesthetics were all unrelated to active transportation. Summary results of relationships for general active transportation with other environmental factors were not applicable.

\section{Physical environment and the relationship with walking for transportation}

Table 9 presents 11 studies that investigated the relationship between the physical environment and walking for transportation. Summary results demonstrated convincing evidence for a strong positive relationship with walkability. Further, transportation walking was unrelated to both access to shops/services/work and access to recreation facilities. Due to a lack of enough separate studies focusing on relationships between the other environmental factors and transportation walking, summary calculations were not applicable here.

\section{Physical environment and the relationship with cycling for transportation}

Summary results for the 19 studies assessing transportation cycling are depicted in Table 10. Convincing evidence for strong positive relationships of cycling for transportation were shown for walkability, access to shops/services/ work and degree of urbanization. This latter finding means that people living in more urbanized areas tended to cycle more for transportation purposes. Possible evidence for a positive association was found between transportation cycling and walking/cycling facilities, whereas evidence showed a possible negative relationship for hilliness. There were no relationships with transportation cycling for access to public transport, access to recreation facilities, traffic- and crime-related safety and aesthetics. Too few individual studies examined relationships between the remaining factors and transportation cycling, so no summary results could be calculated there.

\section{Discussion}

During the past decade, researchers extensively studied the relationship between attributes of the physical environment and different domains of PA in developed countries. Various reviews have been published about this topic, but only a small proportion of findings in these publications refer to European studies. Reviews' conclusions and recommendations for further research therefore mostly rely on North American and Australian

Table 6 Summary results of evidence on the relationship environmental factors and total walking/cycling

\begin{tabular}{|c|c|c|c|c|c|c|c|}
\hline Environm. variables & $\begin{array}{l}\text { Positive } \\
\text { association }\end{array}$ & $\begin{array}{l}\text { Negative } \\
\text { association }\end{array}$ & No association & $A^{*}$ & $\mathrm{~B}^{*}$ & $C^{*}$ & $\mathrm{D}^{*}$ \\
\hline Walkability & & & 61 & 1 & N/A & N/A & N/A \\
\hline Residential density & & & $33^{\mathrm{M}}, 33^{\mathrm{F}}$ & 1 & $\mathrm{~N} / \mathrm{A}$ & $\mathrm{N} / \mathrm{A}$ & $\mathrm{N} / \mathrm{A}$ \\
\hline Land use mix diversity & $33^{\mathrm{F}}$ & & $33^{M}$ & 1 & N/A & $\mathrm{N} / \mathrm{A}$ & $\mathrm{N} / \mathrm{A}$ \\
\hline Street connectivity & & & $33^{\mathrm{M}}, 33^{\mathrm{F}}$ & 1 & N/A & $\mathrm{N} / \mathrm{A}$ & $\mathrm{N} / \mathrm{A}$ \\
\hline Access to shops/services/work & $54,54,54,67$ & & $33^{M}, 33^{F}, 39^{M}, 39^{M}, 39^{F}, 39^{F} 54,54,54,54,54,67$ & 4 & $4 / 16$ & 25 & 00 \\
\hline Access to public transport & $33^{F}$ & & $33^{M}, 93,93$ & 2 & N/A & $\mathrm{N} / \mathrm{A}$ & $\mathrm{N} / \mathrm{A}$ \\
\hline Access to recreation facilities & $54,54,61,92$ & & $\begin{array}{l}33^{M}, 33^{F}, 39^{M}, 39^{M}, 39^{M}, 39^{M}, 39^{F}, 39^{F}, 39^{F}, 39^{F}, \mathbf{6 1}, \\
\mathbf{6 1}, 67, \mathbf{9 2}, \mathbf{9 2}, \mathbf{9 2}, \mathbf{9 2}, \mathbf{9 2}, \mathbf{9 2}, \mathbf{9 2}, \mathbf{9 2}, \mathbf{9 2}, \mathbf{9 2}, \mathbf{9 2}, \mathbf{9 2}, \\
\mathbf{9 2}, \mathbf{9 2}, \mathbf{9 2}, \mathbf{9 2}, \mathbf{9 2}, \mathbf{9 2}, \mathbf{9 2}\end{array}$ & 6 & $4 / 36$ & 11 & 00 \\
\hline Walking/cycling facilities & $26,33^{M}$ & & $33^{\mathrm{M}}, 33^{\mathrm{F}}, 33^{\mathrm{F}}$ & 2 & N/A & $\mathrm{N} / \mathrm{A}$ & $\mathrm{N} / \mathrm{A}$ \\
\hline Safety & 54,71 & & $39^{M}, 39^{M}, 39^{M}, 39^{M}, 39^{F}, 39^{F}, 39^{F}, 39^{F}, 71$ & 3 & $2 / 11$ & 18 & 0 \\
\hline Traffic-related safety & & & $26,33^{M}, 33^{F}, 39^{M}, 39^{M}, 39^{F}, 39^{F}$ & 3 & $0 / 7$ & 0 & 0 \\
\hline Crime-related safety & & & $26,33^{M}, 33^{F}, 67,67$ & 3 & $0 / 5$ & 0 & 0 \\
\hline Aesthetics & 54 & & $33^{\mathrm{M}}, 33^{\mathrm{F}}, 39^{\mathrm{M}}, 39^{\mathrm{M}}, 39^{\mathrm{F}}, 39^{\mathrm{F}}, 54,54,54$ & 3 & $1 / 10$ & 10 & 0 \\
\hline Urbanization & 26,54 & & $42^{\mathrm{M}}, 42^{\mathrm{F}}, 67$ & 3 & $2 / 5$ & 40 & $(+)$ \\
\hline Quality of environment & 71 & 71 & 61 & 2 & N/A & N/A & N/A \\
\hline
\end{tabular}

${ }^{*} A=n^{\circ}$ of independent studies; $B=n^{\circ}$ of associated records divided by all records; $C=\%$ of evidence; $D=$ summary code.

Regular vs italics font $=$ subjective vs objective PA measures; regular vs bold font $=$ subjective vs objective environmental measures

${ }^{M}=$ specific results for males; ${ }^{F}=$ specific results for females. 
Table 7 Summary results of evidence on the relationship environmental factors and recreational walking/cycling

\begin{tabular}{|c|c|c|c|c|c|c|c|}
\hline Environm. variables & Positive association & $\begin{array}{l}\text { Negative } \\
\text { association }\end{array}$ & No association & $A^{*}$ & $\mathrm{~B}^{*}$ & $\mathrm{C}^{*}$ & $D^{*}$ \\
\hline Walkability & $\mathbf{7 8 , 8 3 , 8 5}$ & & $82,82,82^{1}, 82^{2}, 86$ & 5 & $3 / 8$ & 38 & 0 \\
\hline Residential density & & & 34,34 & 1 & N/A & N/A & $\mathrm{N} / \mathrm{A}$ \\
\hline Land use mix diversity & 34 & & 34 & 1 & $\mathrm{~N} / \mathrm{A}$ & $\mathrm{N} / \mathrm{A}$ & $\mathrm{N} / \mathrm{A}$ \\
\hline Street connectivity & & 85 & 34,34 & 2 & N/A & N/A & $\mathrm{N} / \mathrm{A}$ \\
\hline Access to shops/services/work & & & $34,34,63,85$ & 3 & $0 / 4$ & 0 & 0 \\
\hline Access to public transport & & & 34,34 & 1 & N/A & N/A & N/A \\
\hline Access to recreation facilities & $92,92,92$ & $52,52,52$ & $\begin{array}{l}34,34, \mathbf{4} 0^{\mathrm{M}}, \mathbf{4} 0^{\mathrm{M}}, \mathbf{4} 0^{\mathrm{M}}, \mathbf{4} 0^{\mathrm{M}}, \\
\mathbf{4} 0^{\mathrm{F}}, \mathbf{4} 0^{\mathrm{F}}, \mathbf{4} 0^{\mathrm{F}}, \mathbf{4} 0^{\mathrm{F}}, \mathbf{5 2}, 85, \mathbf{9 2}, \\
\mathbf{9 2}, \mathbf{9 2}, \mathbf{9 2}, \mathbf{9 2}, \mathbf{9 2}, \mathbf{9 2}, \mathbf{9 2}, \mathbf{9 2}, \\
\mathbf{9 2}, \mathbf{9 2}, \mathbf{9 2}, \mathbf{9 2}, \mathbf{9 2}, \mathbf{9 2}, \mathbf{9 2}, \mathbf{9 2}\end{array}$ & 5 & $3 / 35$ & 9 & 00 \\
\hline Walking/cycling facilities & 34 & & $34,34,34,85,85$ & 2 & $\mathrm{~N} / \mathrm{A}$ & N/A & $\mathrm{N} / \mathrm{A}$ \\
\hline Safety & 63 & & 85 & 2 & $\mathrm{~N} / \mathrm{A}$ & $\mathrm{N} / \mathrm{A}$ & $\mathrm{N} / \mathrm{A}$ \\
\hline Traffic-related safety & $40^{\mathrm{M}}, 40^{\mathrm{F}}, 41^{\mathrm{M}}, 41^{\mathrm{F}}$ & & $34,34,85$ & 4 & $4 / 7$ & 57 & + \\
\hline Crime-related safety & & & $34,34, \mathbf{4 0}^{\mathrm{M}}, \mathbf{4 0}^{\mathrm{F}}, 63,85$ & 4 & $0 / 6$ & 0 & 00 \\
\hline Aesthetics & 63 & & $34,34,63,63,85$ & 3 & $1 / 6$ & 17 & 0 \\
\hline Urbanization & 84 & & $84,84,84$ & 1 & $\mathrm{~N} / \mathrm{A}$ & $\mathrm{N} / \mathrm{A}$ & $\mathrm{N} / \mathrm{A}$ \\
\hline
\end{tabular}

${ }^{*} A=n^{\circ}$ of independent studies; $B=n^{\circ}$ of associated records divided by all records; $C=\%$ of evidence; $D=$ summary code.

Regular vs italics font $=$ subjective vs objective PA measures; regular vs bold font $=$ subjective vs objective environmental measures.

$\mathrm{M}^{\mathrm{M}}=$ specific results for males; ${ }^{\mathrm{F}}=$ specific results for females; ${ }^{1}=$ specific results for $1^{\text {st }}$ subgroup ${ }^{2}=$ specific results for $2^{\text {nd }}$ subgroup.

study results. Given some clear differences in physical environmental design and physical activity behaviors between North America/Australia and Europe, this raises questions about the applicability of such results in a European context. To our knowledge, this is the first review that summarized specific European results on the relationships between attributes of the physical environment and PA. Despite this lack of European review evidence, the retrieval of 70 eligible papers for the present review shows that the research area is growing in this part of the world. Additionally, the fact that 60 out of the 70 studies were published after 2005 illustrates increasing interest in this topic during the last seven years and the need for an update on the literature in this continent-specific setting, which was the aim of the current review.

The discussion below provides a comparison between our Europe-specific results and outcomes of previous, non-continent-specific reviews, in order to reveal the most important differences and similarities. Our European summary results indicated convincing evidence for relationships with five environmental factors: walkability was positively related to total $\mathrm{PA}$, transportation walking and transportation cycling, and access to shops/services/work was positively related to both general active transportation and transportation cycling. Safety from traffic showed a positive association with recreational walking/cycling, while evidence for urbanization degree revealed a positive relationship with transportation cycling and a negative relationship with total PA. Lastly, quality of the environment was positively related to total PA. This evidence primarily revealed that the majority of above-mentioned environmental attributes were more frequently associated with transportation PA, compared to recreational PA. For instance, the factors walkability, access to shops/services/ work and urbanization degree were all unrelated to recreational PA, despite their associations with transportation PA. Most earlier reviews that focused mainly on nonEuropean walking and cycling studies found comparable results. Associations of walkability with active travel were observed in the review of Panter and Jones [16] and two other non-Europe-specific reviews reported positive associations with utilitarian walking/biking trips, but not with trips for exercise or recreation $[10,12]$. A similar pattern in worldwide review evidence is present for access to shops/services/work. For instance, Duncan and colleagues [13] observed positive relationships with total PA, and reviews by Owen and colleagues [12] and Panter and Jones [16] identified positive associations with total walking and active travel, respectively. Saelens and Handy [15] found consistent associations with walking for transportation, whereas little or no evidence was observed with total and recreational walking. This patterning of findings for both non-Europe-specific as our European results might refer to a more prominent role of the above-mentioned environmental attributes in the transportation PA domain, rather than the recreational. Namely, higher walkability translates into a higher density and easier accessibility of destinations, such as work, which is especially inviting for PA with a transportation purpose. Recreational activities may be less dependent on the convenience of a route or the proximity of destinations. Moreover, it is possible that 
Table 8 Summary results of evidence on the relationship environmental factors and general active transportation

\begin{tabular}{|c|c|c|c|c|c|c|c|}
\hline Environm. variables & Positive association & $\begin{array}{l}\text { Negative } \\
\text { association }\end{array}$ & No association & $A^{*}$ & $\mathrm{~B}^{*}$ & $\mathrm{C}^{*}$ & $D^{*}$ \\
\hline Residential density & & & 34,34 & 1 & N/A & N/A & N/A \\
\hline Land use mix diversity & $34,34,62^{\mathrm{M}}, 62^{\mathrm{F}}, 62^{\mathrm{F}}$ & $62^{\mathrm{M}}, 62^{\mathrm{F}}$ & $62^{\mathrm{M}}$ & 2 & N/A & N/A & N/A \\
\hline Street connectivity & $62^{\mathrm{M}}, 62^{\mathrm{F}}, 62^{\mathrm{M}}, 62^{\mathrm{F}}, 62^{\mathrm{M}}, 62^{\mathrm{F}}$ & & 34,34 & 2 & N/A & N/A & $\mathrm{N} / \mathrm{A}$ \\
\hline Access to shops/services/work & 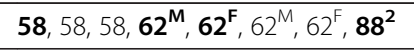 & & $34,34, \mathbf{5 7}, \mathbf{8 8}^{\mathbf{1}}$ & 5 & $8 / 12$ & 67 & + \\
\hline Access to public transport & & & $34,34,57$ & 2 & $\mathrm{~N} / \mathrm{A}$ & $\mathrm{N} / \mathrm{A}$ & $\mathrm{N} / \mathrm{A}$ \\
\hline Access to recreation facilities & & & $34,34,58, \mathbf{6 2}^{\mathrm{M}}, \mathbf{6 2}^{\mathrm{F}}$ & 3 & $0 / 5$ & 0 & 0 \\
\hline Walking/cycling facilities & 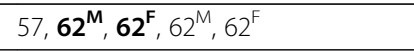 & & $34,34,34,34,58$ & 4 & $5 / 10$ & 50 & $(+)$ \\
\hline Traffic-related safety & $62^{\mathrm{F}}, 62^{\mathrm{M}}, 62^{\mathrm{F}}, 62^{\mathrm{M}}, 62^{\mathrm{F}}, 62^{\mathrm{M}}, 62^{\mathrm{F}}$ & $\begin{array}{l}58,62^{\mathrm{M}}, 62^{\mathrm{F}}, 62^{\mathrm{M}}, \\
62^{\mathrm{F}}, 62^{\mathrm{M}}, 62^{\mathrm{M}}\end{array}$ & 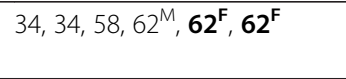 & 3 & $7 / 20$ & 35 & 0 \\
\hline Crime-related safety & $62^{\mathrm{F}}, 62^{\mathrm{M}}$ & & $34,34,58, \mathbf{6 2}^{\mathrm{M}}, 62^{\mathrm{F}}, \mathbf{8 8}^{\mathbf{1}}, \mathbf{8 8}^{\mathbf{2}}$ & 4 & $2 / 9$ & 22 & 00 \\
\hline Aesthetics & & $88^{1}$ & $\begin{array}{l}34,34,58,62^{\mathrm{M}}, 62^{\mathrm{F}} \mathbf{8 8}^{\mathbf{1}}, \mathbf{8 8}^{\mathbf{1}} \\
\mathbf{8 8}^{\mathbf{2}}, \mathbf{8 8}^{\mathbf{2}}, \mathbf{8 8}^{\mathbf{2}}\end{array}$ & 3 & $1 / 11$ & 9 & 0 \\
\hline Urbanization & $62^{\mathrm{M}}, 62^{\mathrm{F}}$ & $51^{\mathrm{M}}, 51^{\mathrm{F}}$ & $62^{\mathrm{M}}, 62^{\mathrm{F}}$ & 2 & $\mathrm{~N} / \mathrm{A}$ & $\mathrm{N} / \mathrm{A}$ & $\mathrm{N} / \mathrm{A}$ \\
\hline
\end{tabular}

* $A=n^{\circ}$ of independent studies; $B=n^{\circ}$ of associated records divided by all records; $C=\%$ of evidence; $D=$ summary code.

Regular vs italics font = subjective vs objective PA measures; regular vs bold font = subjective vs objective environmental measures.

$M^{M}$ specific results for males; ${ }^{F}=$ specific results for females; ${ }^{1}=$ specific results for $1^{\text {st }}$ subgroup; ${ }^{2}=$ specific results for $2^{\text {nd }}$ subgroup.

PA for recreational purposes is not necessarily undertaken in the neighborhood, whereas physical environmental measures mostly refer to the residential environment. In the same line, a higher degree of urbanization translates into denser areas, with more destinations that can be easily reached by bike, which might explain our convincing evidence on a positive relationship of urbanization degree with transportation cycling. However, our findings also indicated counter-intuitive evidence concerning urbanization, i.e., a negative association with total PA. Yet, in this case it is possible that occupational or domesticoriented activities like gardening, rather than activities with a transportation or sports/exercise purpose, made the largest contribution to the total PA measures in the involved studies, and suburban or rural places lend themselves more for such pursuits than urban ones. Our convincing evidence on a positive relationship between quality of the environment and total PA contrasts with an earlier, non-Europe-specific review [9]. In that paper, the authors did not find a relationship between a similar environmental "combined scale" and total PA. Our results, however, might indicate that the cumulative contribution of several physical environmental aspects does have an impact on European health behavior, apart from the individual influence of separate environmental attributes. Yet, quality of the environment was insufficiently investigated in relation to other PA domains, which makes it hard to draw definite conclusions.

Table 9 Summary results of evidence on the relationship environmental factors and transportation walking

\begin{tabular}{|c|c|c|c|c|c|c|c|}
\hline Environm. variables & Positive association & $\begin{array}{l}\text { Negative } \\
\text { association }\end{array}$ & No association & $A^{*}$ & $\mathrm{~B}^{*}$ & $C^{*}$ & $D^{*}$ \\
\hline Walkability & $\mathbf{7 8}, \mathbf{8 2}, \mathbf{8 3}, 85, \mathbf{8 6}$ & & 82 & 5 & $4 / 5$ & 80 & ++ \\
\hline Street connectivity & & & 85 & 1 & $\mathrm{~N} / \mathrm{A}$ & $\mathrm{N} / \mathrm{A}$ & $\mathrm{N} / \mathrm{A}$ \\
\hline Access to shops/services/work & 63,77 & 85 & 77 & 3 & $2 / 4$ & 50 & 0 \\
\hline Access to public transport & 50 & & & 1 & $\mathrm{~N} / \mathrm{A}$ & $\mathrm{N} / \mathrm{A}$ & $\mathrm{N} / \mathrm{A}$ \\
\hline Access to recreation facilities & & & $\begin{array}{l}\mathbf{5 2}, \mathbf{5 2}, 85, \mathbf{9 2}, \mathbf{9 2}, \mathbf{9 2}, \mathbf{9 2} \\
\mathbf{9 2}, \mathbf{9 2}, \mathbf{9 2}, \mathbf{9 2}, \mathbf{9 2}, \mathbf{9 2}\end{array}$ & 3 & $0 / 13$ & 0 & 0 \\
\hline Walking/cycling facilities & & & 85,85 & 1 & $\mathrm{~N} / \mathrm{A}$ & $\mathrm{N} / \mathrm{A}$ & $\mathrm{N} / \mathrm{A}$ \\
\hline Safety & & & 63,85 & 2 & $\mathrm{~N} / \mathrm{A}$ & $\mathrm{N} / \mathrm{A}$ & $\mathrm{N} / \mathrm{A}$ \\
\hline Traffic-related safety & & & 85 & 1 & N/A & N/A & $\mathrm{N} / \mathrm{A}$ \\
\hline Crime-related safety & & & 63,85 & 2 & N/A & N/A & N/A \\
\hline Aesthetics & 63 & 63,85 & 63,85 & 2 & N/A & N/A & $\mathrm{N} / \mathrm{A}$ \\
\hline Urbanization & 84,84 & & & 1 & $\mathrm{~N} / \mathrm{A}$ & N/A & N/A \\
\hline Quality of environment & & & $77^{\mathrm{M}}, 77^{\mathrm{F}}$ & 1 & $\mathrm{~N} / \mathrm{A}$ & $\mathrm{N} / \mathrm{A}$ & $\mathrm{N} / \mathrm{A}$ \\
\hline
\end{tabular}

* $A=n^{\circ}$ of independent studies; $B=n^{\circ}$ of associated records divided by all records; $C=\%$ of evidence; $D=$ summary code.

Regular vs italics font = subjective vs objective PA measures; regular vs bold font $=$ subjective vs objective environmental measures

${ }^{M}=$ specific results for males; ${ }^{F}=$ specific results for females. 
Table 10 Summary results of evidence on the relationship environmental factors and transportation cycling

\begin{tabular}{|c|c|c|c|c|c|c|c|}
\hline Environm. variables & Positive association & $\begin{array}{l}\text { Negative } \\
\text { association }\end{array}$ & No association & $A^{*}$ & $\mathrm{~B}^{*}$ & $C^{*}$ & $D^{*}$ \\
\hline Walkability & $59, \mathbf{8 3}, 85, \mathbf{8 6}$ & & 82,82 & 5 & $4 / 6$ & 67 & ++ \\
\hline Residential density & $53^{\mathrm{M}, 1}, 53^{\mathrm{F}, 1}$ & & $53^{\mathrm{M}, 2}, 53^{\mathrm{M}, 3}, 53^{\mathrm{F}, 2}, 53^{\mathrm{F}, 3}$ & 1 & $\mathrm{~N} / \mathrm{A}$ & $\mathrm{N} / \mathrm{A}$ & N/A \\
\hline$\underline{\text { Land use mix diversity }}$ & & & 80 & 1 & N/A & N/A & N/A \\
\hline Street connectivity & 85 & & & 1 & N/A & $\mathrm{N} / \mathrm{A}$ & N/A \\
\hline Access to shops/services/work & 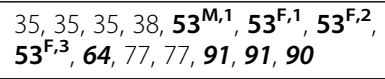 & & $53^{\mathrm{M}, 2}, \mathbf{5 3 ^ { \mathrm { M } , 3 }}, 77,77,85$ & 7 & $14 / 19$ & 74 & ++ \\
\hline Access to public transport & 50 & & $35,53^{\mathrm{M}, 1}, 53^{\mathrm{M}, 2}, 53^{\mathrm{M}, 3}, 53^{\mathrm{F}, 1}, 53^{\mathrm{F}, 2}, 53^{\mathrm{F}, 3}$ & 3 & $1 / 8$ & 13 & 0 \\
\hline Access to recreation facilities & 85,91 & 52 & $52,92,92,92,92,92,92,92,92,92,92$ & 5 & $2 / 14$ & 14 & 0 \\
\hline Walking/cycling facilities & $64,64,64,80,90,91$ & & $35,35, \mathbf{6 4}, \mathbf{6 4}, \mathbf{6 4}, 80,85,85$ & 6 & $6 / 14$ & 43 & $(++)$ \\
\hline Safety & & & 80,85 & 2 & $\mathrm{~N} / \mathrm{A}$ & N/A & N/A \\
\hline Traffic-related safety & $41^{\mathrm{M}}, 41^{\mathrm{F}}, 64,90,91$ & $79^{2}, \mathbf{9 1}, 91$ & $35,35,35,35,64,79^{1}, 80,85$ & 8 & $5 / 16$ & 31 & 00 \\
\hline Crime-related safety & $79^{2}, 85,90$ & 91 & $35,35,79^{1}, \mathbf{9 0}, 91$ & 5 & $3 / 9$ & 33 & 0 \\
\hline Aesthetics & $79^{1}$ & 91 & $79^{2}, 80$ & 3 & $1 / 4$ & 25 & 0 \\
\hline Urbanization & $35,64,84,90,90,91,91,91$ & & 84 & 5 & $8 / 9$ & 89 & ++ \\
\hline Hilliness & 80 & 64,91 & & 3 & $2 / 3$ & 67 & $(-)$ \\
\hline Quality of environment & & & $77^{\mathrm{M}}, 77^{\mathrm{M}}, 77^{\mathrm{F}}, 77^{\mathrm{F}}$ & 1 & $\mathrm{~N} / \mathrm{A}$ & N/A & N/A \\
\hline
\end{tabular}

${ }^{*} A=n^{\circ}$ of independent studies; $B=n^{\circ}$ of associated records divided by all records; $C=\%$ of evidence; $D=$ summary code.

Regular vs italics font $=$ subjective vs objective PA measures; regular vs bold font $=$ subjective vs objective environmental measures .

$\mathrm{M}=$ specific results for males; ${ }^{\mathrm{F}}=$ specific results for females; ${ }^{1}=$ specific results for $1^{\text {st }}$ subgroup; ${ }^{2}=$ specific results for $2^{\text {nd }}$ subgroup; ${ }^{3}=$ specific results for $3^{\text {rd }}$ subgroup.

Our review's summary results further yielded possible evidence on relationships with different PA domains for five environmental factors: access to recreation facilities was positively related to total PA, while presence and quality of walking/cycling facilities showed positive relationships with general active transportation and cycling for transportation. Urbanization degree was positively associated with total walking/cycling and the composite factor quality of the environment was positively related to LTPA. For the factor hilliness, possible evidence for a negative relationship was found with cycling for transportation. Similar to the convincing evidence, most possible relationships of environmental attributes were found in relation to transportation PA, rather than recreational PA. The positive relationship of active transport and transportation cycling with walking/cycling facilities and the negative association of transportation cycling with hilliness were found in the expected directions, as the results probably refer to the importance of respectively adequate infrastructure and the need for absence of difficulties during active transportation. Moreover, cycling for transport is a more common behavior in Europe compared to other continents [21], which may also explain the observed associations within the European studies. Worldwide evidence on the role of walking/cycling facilities is conflicting. One non-Europe-specific review [14] supports our findings by showing positive associations with commuting activities and a metaanalysis by Duncan and colleagues [13] observed positive relationships with total PA. By contrast, other reviews on worldwide studies identified either inconsistent results $[16,103]$, or a lack of evidence for relationships with transportation PA, while positive relationships with recreational PA did appear $[12,15]$. Because of the abovementioned inconsistencies in the existing worldwide review evidence and the fact that our own review results show less strong relationships (possible evidence), more studies need to reveal whether walking/cycling infrastructure plays an important role as a correlate of PA, and whether the strength of the relationship is more consistent for the transportation or recreational PA domain. In addition, more research on relationships between hilliness and PA is needed, as non-Europe-specific reviews also observed inconsistencies about the direction of associations with different PA domains [11,14].

Neighborhood aesthetics and safety from crime were the two environmental factors unrelated to several PA domains. In addition, the factors access to recreation facilities and traffic safety also showed a low importance in relation to specific PA domains. By way of comparison, concerning aesthetics, one non-Europe-specific review observed a lack of association between aesthetics and several PA domains [14] and another literature review [16] identified inconsistent relationships with active travel. Conversely, other worldwide literature reviews did find positive relationships with total PA $[9,103]$ and with recreational and total walking, but not with transportation walking $[12,15]$. Furthermore, results in the non-Europe-specific literature are ambiguous when crime-related safety $[9,15,104]$, as well as safety from 
traffic $[9,12-16]$ are considered. Where certain reviews on worldwide studies found positive relationships between these two forms of safety and PA [9,13,104], others reported inconsistent or unrelated results regarding both safety from crime [15] and safety from traffic [12,14-16] with transportation and recreational PA. The present review's unrelated results might indicate that, from a European PA perspective, aesthetics and safety levels are not so important. It is plausible that differences between low and high levels of these environmental factors are less pronounced in Europe, when compared to other geographical regions like North America, and other environmental attributes might outweigh the influence of these factors. Also the low importance of access to recreation facilities in the present review is in contrast with earlier non-Europe-specific reviews, where positive associations between access to recreation facilities and different PA domains did appear $[9,13,14,16]$. Especially the absence of relationships with recreational PA is unexpected. An explanation might again be that in Europe, leisure-time physical activity and recreational walking/cycling are done elsewhere than in the residential neighborhood, while most environmental measures refer to these residential areas, and environmental features of the places where recreational activities are undertaken may differ from those measured. Moreover, the recreational facilities may be situated too far from the home residence in order to be reached on foot or by bike, which could explain our unassociated findings in the domain of transportation PA. Another explanation for the European lack of associations is that the vast majority of these measurements were based on perceptions, so inter-individual differences in interpretations could contribute to the unrelated summary scores.

\section{Strengths}

A first strength of the current study is its exclusive focus on European research, as it was not entirely clear yet if recommendations based on predominantly non-Europefocused reviews would be applicable to the development of adequate interventions in this continent. Indeed, some of our summary results are conflicting with earlier, worldwide reviews, which supports the need for Europe-specific approaches. Secondly, we were able to summarize a large amount of studies that were previously unmentioned by other reviews in this research field, pointing out the importance of updating the evidence. Further, as researchers already have shown that particular domains of PA relate differently to certain measures of the physical environment $[10,12,14]$, summarizing relationships according to specific domains of PA is a third strength of the current systematic review.

\section{Limitations}

As some of the environmental factors were understudied in relation to specific PA domains, a first limitation of this systematic review is that we could not calculate a number of PA-domain-specific summary results. Therefore, we were not able to complete the existing worldwide evidence in all PA domains, regarding all included environmental attributes. A second limitation refers to the design of the studies: all included studies, except one, were cross-sectional. As a consequence, we could not ensure that our convincing and possible evidence refers to causal relationships between the environment and PA. Thirdly, as shown in Table 2, the largest part of studies were conducted in Western Europe (i.e., The U.K., Belgium and The Netherlands) while studies in Eastern Europe contributed the least to the total amount of publications. One of the reasons for this disproportion in geographical region might be the restriction for Englishwritten publications. As a consequence, certain specific summary results (e.g., relationships between total PA and walkability) are dominantly determined by findings from Western European countries (e.g., Belgium). Since a broad inter-regional variety in cultural, policy and physical environmental aspects is present nowadays within the European continent itself, this overrepresentation may have biased the results. Therefore, caution should be paid when these results are generalized to other geographical areas, such as Eastern Europe. A last limitation of this review is that a quality assessment of the included studies was lacking. Therefore, some of the summary results may have been based upon the findings of methodological weaker studies, which, in turn, increased the risk of bias.

\section{Recommendations for future research}

A first suggestion for future research is to expand the amount of European studies concerning relationships between physical environmental attributes and separate domains of PA. This review revealed that total PA was the most commonly used measure of PA, while some other domain-specific PA measures are lacking in relation to various environmental factors. Our findings show that following specific environmental attributes are still understudied in Europe: the three walkability components (i.e., residential density, land use mix diversity and street connectivity), access to public transportation, quality and presence of walking and cycling facilities, hilliness and general measures of the environmental quality. Future European research should therefore challenge the lack of studies on these attributes' relations with domain-specific PA, in order to complete the existing worldwide evidence. Second, to encounter the abovementioned underrepresentation of Eastern European studies, also the amount of studies on the relationship 
between the physical environment and different PA domains in this part of the continent should be expanded. A third recommendation relates to the used methods for assessment of environmental attributes. Our results indicated that the majority of included studies used environmental perceptions, while only a limited amount of studies included objective assessments of the physical environment. Objective and perceived measures of the physical environment have been shown to relate differently to PA [102], so an increase in studies combining both objective and subjective environmental measures is encouraged. Fourth, more longitudinal studies in the research field are needed in order to reveal the influence of (changes in) physical environmental attributes on different PA domains, in order to facilitate the development of appropriate and effective interventions for promoting PA. At last, given the fact that this review identified some clear inter-continental differences concerning the relationship between the physical environment and domain-specific PA in adults, it is plausible that the environmental correlates of $\mathrm{PA}$ in other age groups might also be continent- or region-specific. Hence, it would be interesting to compare the current review evidence on adults with that of other age groups, such as young adults with little children, or older adults.

\section{Conclusions}

Our summary results revealed several relationships between the physical environment and different domains of PA. Transportation PA, rather than PA with a recreational purpose, appears to be more consistently related to the physical environment. First, convincing evidence on positive relationships between particular domains of PA emerged for the environmental attributes walkability, access to shops/services/work and environmental quality, and this evidence contributed to a more complete view on the existing evidence worldwide. However, causal relationships could not be revealed yet, because longitudinal studies were absent. Next, there was possible evidence on a positive relationship for transportation PA and walking/cycling facilities, and on a negative relationship of transportation cycling with hilliness. Although these findings seem promising in completing existing knowledge, this possible evidence is less strong than the convincing results we found for other environmental factors, such as walkability, and needs more rigorous investigation before generalizations can be made. The lack of associations between domain-specific PA and access to recreation facilities, aesthetics, crimeand traffic-related safety was contrasting with earlier, non-Europe-specific reviews. This suggests that these factors might play a less important role from a European PA perspective. At last, the relationship between a considerable amount of environmental attributes and particular PA domains is still understudied in European research. Therefore, increasing research on relationships between PA and the three walkability components (i.e., residential density, land use mix diversity and street connectivity), access to public transportation, quality and presence of walking and cycling facilities, hilliness and general measures of the environmental quality is highly encouraged.

\section{Additional file}

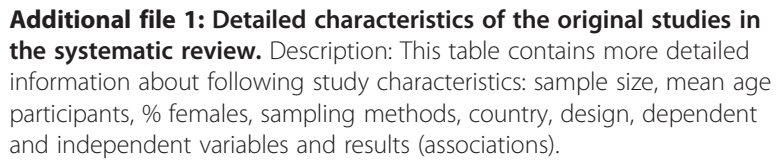

\section{Abbreviations}

PA: Physical activity; MVPA: Moderate-to-vigorous physical activity; LTPA: Leisure-time physical activity.

\section{Competing interests}

The authors declare that they have no competing interests.

\section{Authors' contributions}

IDB, BD, JVC and WH developed the search strategy; WH and JVC conducted the systematic search of electronic databases and screening; $W H$ undertook the data extraction, summary calculation, drafting of the tables and writing of the manuscript, supervised by IDB and BD; IDB, BD, JVC, LG, LM and NVdW contributed to critical revision of the manuscript, and all approved the final version.

\section{Acknowledgements}

This research was supported by Fund for Scientific Research Flanders (FWO) B/10825/02

\section{Author details}

'Department of Movement and Sports Sciences, Ghent University, Watersportlaan 2, B-9000 Ghent, Belgium. ²Department of Human Biometry and Biomechanics, Vrije Universiteit Brussel, Pleinlaan 2, B-1050 Brussels, Belgium. ${ }^{3}$ Department of Experimental Clinical and Health Psychology, Ghent University, Henri Dunantlaan 2, B-9000 Ghent, Belgium. ${ }^{4}$ Department of Public Health, Ghent University, De Pintelaan 185 (Block A), B-9000 Ghent, Belgium. ${ }^{5}$ Department of Geography, Ghent University, Krijgslaan 281 (S8), B-9000 Ghent, Belgium.

Received: 7 May 2012 Accepted: 13 September 2012

Published: 19 September 2012

\section{References}

1. U.S.Department Of Health And Human Services: Physical Activity and Health: A Report of the Surgeon General. Atlanta, Georgia: USDHSS, Centers for Disease Control and Prevention; 1996.

2. Warburton D, Nicol C, Bredin S: Health benefits of physical activity: the evidence. Can Med Assoc J 2006, 174:801-809.

3. Oja P, Titze S, Bauman A, de Geus B, Krenn P, Reger-Nash B, et al: Health benefits of cycling: a systematic review. Scand J Med Sci Spor 2011, 21:496-509.

4. Physical Inactivity: a global public health problem., http://www.who.int/ dietphysicalactivity/factsheet_inactivity/en/index.html.

5. McLeroy K, Bibeau D, Steckler A, Glanz K: An ecological perspective on health promotion programs. Health Educ Q 1988, 15:351-377.

6. Sallis JF, Cervero RB, Ascher W, Henderson KA, Kraft MK, Kerr J: An ecological approach to creating active living communities. Annu Rev Public Health 2006, 27:297-322. 
7. Richard L, Gauvin L, Raine K: Ecological models revisited: their uses and evolution in health promotion over two decades. In Annu Rev Public Health:; 2011:307-326.

8. Davison KK, Lawson CT: Do attributes in the physical environment influence children's physical activity? A review of the literature. Int J Behav Nutr Phys Act 2006, 3:19.

9. Humpel N, Owen N, Leslie E: Environmental factors associated with adults' participation in physical activity - A review. Am J Prev Med 2002, 22:188-199.

10. Saelens BE, Sallis JF, Frank LD: Environmental correlates of walking and cycling: Findings from the transportation, urban design, and planning literatures. Ann Behavioral Med 2003, 25:80-91.

11. McCormack G, Giles-Corti B, Lange A, Smith T, Martin K, Pikora TJ: An update of recent evidence of the relationship between objective and self-report measures of the physical environment and physical activity behaviours. J Sci Med Sport 2004, 7:81-92.

12. Owen N, Humpel N, Leslie E, Bauman A, Sallis JF: Understanding environmental influences on walking - Review and research agenda. Am J Prev Med 2004, 27:67-76.

13. Duncan MJ, Spence JC, Mummery WK: Perceived environment and physical activity: a meta-analysis of selected environmental characteristics. Int J Behav Nutr Phys Act 2005, 2:11

14. Wendel-Vos W, Droomers M, Kremers S, Brug J, van Lenthe F: Potential environmental determinants of physical activity in adults: a systematic review. Obes Rev 2007, 8:425-440.

15. Saelens BE, Handy SL: Built environment correlates of walking: A review. Med Sci Sports Exerc 2008, 40:S550-S566.

16. Panter JR, Jones $\mathrm{A}$ : Attitudes and the environment as determinants of active travel in adults: what do and don't we know? J Phys Act Health 2010, 7:551-561

17. Cummins S, Macintyre S: Food environments and obesity neighbourhood or nation? Int J Epidemiol 2006, 35:100-104.

18. Rodrigue J-P, Comtois C, Slack B: The Geography of Transport Systems. 2nd edition. New York: Routledge; 2009.

19. Pucher J, Buehler R: Making cycling irresistible: Lessons from the Netherlands, Denmark and Germany. Transp Rev 2008 28:495-528

20. Forsyth A, Krizek K: Promoting walking and bicyling: assessing the evidence to assist planners. Built Environment 2010, 36:429-446.

21. Bassett DR, Pucher J, Buehler R, Thompson DL, Crouter SE: Walking, cycling, and obesity rates in Europe, North America, and Australia. J Phys Act Health 2008, 5:795-814.

22. Sugiyama T, Neuhaus M, Cole R, Giles-Corti B, Owen N: Destination and Route Attributes Associated with Adults' Walking: A Review. Med Sci Sports Exer 2012, 44:1275-1286.

23. Moher D, Liberati A, Tetzlaff J, Altman DG: Preferred Reporting Items for Systematic Reviews and Meta-Analyses: The PRISMA Statement. J Clin Epid 2009, 62:1006-1012.

24. Bamana A, Tessier S, Vuillemin A: Association of perceived environment with meeting public health recommendations for physical activity in seven European countries. J Public Health 2008, 30:274-281.

25. Bergman P, Grjibovski AM, Hagstromer M, Bauman A, Sjostrom M: Adherence to physical activity recommendations and the influence of socio-demographic correlates - a population-based cross-sectional study. BMC Public Health 2008, 8:367.

26. Bergman P, Grjibovski AM, Hagstromer M, Sallis JF, Sjostrom M: The association between health enhancing physical activity and neighbourhood environment among Swedish adults - a populationbased cross-sectional study. Int J Behav Nutr Phys Act 2009, 6:8

27. Bertrais S, Preziosi P, Mennen L, Galan P, Hercberg S, Oppert JM: Sociodemographic and geographic correlates of meeting current recommendations for physical activity in middle-aged French adults: the Supplementation en Vitamines et Mineraux Antioxydants (SUVIMAX) Study. Am J Public Health 2004, 94:1560-1566.

28. Bjork J, Albin M, Grahn P, Jacobsson H, Ardo J, Wadbro J, et al: Recreational values of the natural environment in relation to neighbourhood satisfaction, physical activity, obesity and wellbeing. J Epidemiol Community Health 2008, 62:e2.

29. Bolivar J, Daponte A, Rodriguez M, Sanchez JJ: The influence of individual, social and physical environment factors on physical activity in the adult population in Andalusia, Spain. Int J Environ Res Public Health 2010, 7:60-77.
30. Bonnefoy XR, Braubach M, Moissonnier B, Monollbaev K, Robbel N: Housing and health in Europe: preliminary results of a pan-European study. Am J Public Health 2003, 93:1559-1563.

31. Cochrane T, Davey RC, Gidlow C, Smith GR, Fairburn J, Armitage CJ, et al: Small area and individual level predictors of physical activity in urban communities: a multi-level study in Stoke on Trent, England. Int J Environ Res Public Health 2009, 6:654-677

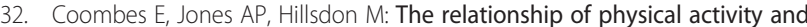
overweight to objectively measured green space accessibility and use. Soc Sci Med 2010, 70:816-822.

33. De Bourdeaudhuij I, Sallis JF, Saelens BE: Environmental correlates of physical activity in a sample of Belgian adults. Am J Health Promot 2003, 18:83-92.

34. De Bourdeaudhuij I, Teixeira PJ, Cardon G, Deforche B: Environmental and psychosocial correlates of physical activity in Portuguese and Belgian adults. Public Health Nutr 2005, 8:886-895.

35. de Geus B, De Bourdeaudhuij I, Jannes C, Meeusen R: Psychosocial and environmental factors associated with cycling for transport among a working population. Health Educ Res 2008, 23:697-708.

36. Dygryn J, Mitas J, Stelzer J: The influence of built environment on walkability using Geographic Information System. J Hum Kinet 2010, 24:93-99.

37. Ellaway A, Macintyre S, Bonnefoy X: Graffiti, greenery, and obesity in adults: secondary analysis of European cross sectional survey. Br Med J 2005, 331:611-612.

38. Engbers LH, Hendriksen IJ: Characteristics of a population of commuter cyclists in the Netherlands: perceived barriers and facilitators in the personal, social and physical environment. Int J Behav Nutr Phys Act 2010, 7:89.

39. Foster C, Hillsdon M, Thorogood M: Environmental perceptions and walking in English adults. J Epidemiol Community Health 2004, 58:924-928.

40. Foster C, Hillsdon M, Jones A, Grundy C, Wilkinson P, White M, et al: Objective measures of the environment and physical activity - results of the Environment and Physical Activity Study in English adults. J Phys Act Health 2009, 6:570-580.

41. Foster CE, Panter JR, Wareham NJ: Assessing the impact of road traffic on cycling for leisure and cycling to work. Int J Behav Nutr Phys Act 2011, 8:61.

42. Fromel K, Mitas J, Kerr J: The associations between active lifestyle, the size of a community and SES of the adult population in the Czech Republic. Health Place 2009, 15:447-454.

43. Gast GC, Frenken FJ, van Leest LA, Wendel-Vos GC, Bemelmans WJ: Intranational variation in trends in overweight and leisure time physical activities in The Netherlands since 1980: stratification according to sex, age and urbanisation degree. Int J Obes (Lond) 2007, 31:515-520.

44. Gidlof-Gunnarsson A, Ohrstrom E: Noise and well-being in urban residential environments: the potential role of perceived availability to nearby green areas. Landsc Urban Plan 2007, 83:115-126.

45. Guthold R, Ono T, Strong KL, Chatterji S, Morabia A: Worldwide variability in physical inactivity - A 51-country survey. Am J Prev Med 2008 34:486-494.

46. Harrison RA, Gemmell I, Heller RF: The population effect of crime and neighbourhood on physical activity: an analysis of 15,461 adults. J Epidemiol Community Health 2007, 61:34-39.

47. Hillsdon $\mathrm{M}$, Panter J, Foster $\mathrm{C}$, Jones $\mathrm{A}$ : The relationship between access and quality of urban green space with population physical activity. Public Health 2006, 120:1127-1132.

48. Jones A, Hillsdon M, Coombes E: Greenspace access, use, and physical activity: Understanding the effects of area deprivation. Prev 2009, 49:500-505.

49. Kamphuis CB, van Lenthe FJ, Giskes K, Huisman M, Brug J, Mackenbach JP. Socioeconomic status, environmental and individual factors, and sports participation. Med Sci Sports Exerc 2008, 40:71-81.

50. Keijer MJN, Rietveld P: How do people get to the railway station? The Dutch experience. Transport Plan Techn 2000, 23:215-235.

51. Kwasniewska M, Kaczmarczyk-Chalas K, Pikala M, Broda G, Kozakiewicz K, Pajak A, et al: Socio-demographic and lifestyle correlates of commuting activity in Poland. Prev Med 2010, 50:257-261.

52. Maas J, Verheij RA, Spreeuwenberg P, Groenewegen PP: Physical activity as a possible mechanism behind the relationship between green space and health: A multilevel analysis. BMC Public Health 2008, 8:206. 
53. Maat K, Timmermans HJP: Influence of the residential and work environment on car use in dual-earner households. Transp Res: Part A: Pol Practice 2009, 43:654-664.

54. Mason P, Kearns A, Bond L: Neighbourhood walking and regeneration in deprived communities. Health Place 2011, 17:727-737.

55. Miles R: Neighborhood disorder, perceived safety, and readiness to encourage use of local playgrounds. Am J Prev Med 2008, 34:275-281.

56. Milosevic M, Golubic R, Mustajbegovic J, Jelinic JD, Holcer NJ, Kern J: Regional pattern of physical inactivity in Croatia. Coll Antropol 2009, 33:35-38.

57. Molina-Garcia J, Castillo I, Sallis JF: Psychosocial and environmental correlates of active commuting for university students. Prev Med 2010, 51:136-138

58. Ogilvie D, Mitchell R, Mutrie N, Petticrew M, Platt S: Personal and environmental correlates of active travel and physical activity in a deprived urban population. Int J Behav Nutr Phys Act 2008, 5:43.

59. Owen N, De Bourdeaudhuij I, Sugiyama T, Leslie E, Cerin E, Van Dyck D, Bauman A: Bicycle use for transport in an Australian and a Belgian city: associations with built-environment attributes. J Urban Health 2010, 87:189-198

60. Panter J, Jones A, Hillsdon M: Equity of access to physical activity facilities in an English city. Prev Med 2008, 46:303-307.

61. Panter JR, Jones AP: Associations between physical activity, perceptions of the neighbourhood environment and access to facilities in an English city. Soc Sci Med 2008, 67:1917-1923.

62. Panter JR, Jones AP, Van Sluijs EM, Griffin SJ, Wareham NJ: Environmental and psychological correlates of older adult's active commuting. Med Sci Sports Exerc 2011, 43:1235-1243.

63. Parkes A, Kearns A: The multi-dimensional neighbourhood and health: a cross-sectional analysis of the Scottish Household Survey, 2001. Health Place 2006, 12:1-18.

64. Parkin J, Wardman M, Page M: Estimation of the determinants of bicycle mode share for the journey to work using census data. Transportation 2008, 35:93-109.

65. Pascual C, Regidor E, Martinez D, Elisa CM, Dominguez V: Socioeconomic environment, availability of sports facilities, and jogging, swimming and gym use. Health Place 2009, 15:553-561

66. Pitsavos C, Panagiotakos DB, Lentzas Y, Stefanadis C: Epidemiology of leisure-time physical activity in socio-demographic, lifestyle and psychological characteristics of men and women in Greece: the ATTICA Study. BMC Public Health 2005, 5:37.

67. Poortinga W: Perceptions of the environment, physical activity, and obesity. Soc Sci Med 2006, 63:2835-2846.

68. Rutten A, Abel T, Kannas L, von Lengerke T, Luschen G, Diaz JAR, et al: Self reported physical activity, public health, and perceived environment: results from a comparative European study. J Epidemiol Community Health 2001, 55:139-146.

69. Rutten A, Abu-Omar K: Perceptions of environmental opportunities for physical activity in the European Union. Soz Praventiv Med 2004, 49:310-317.

70. Santana P, Santos R, Nogueira $H$ : The link between local environment and obesity: a multilevel analysis in the Lisbon Metropolitan Area, Portugal. Soc Sci Med 2009, 68:601-609.

71. Santos MS, Vale MS, Miranda L, Mota J: Socio-demographic and perceived environmental correlates of walking in Portuguese adults-a multilevel analysis. Health Place 2009, 15:1094-1099.

72. Santos R, Silva P, Santos P, Ribeiro JC, Mota J: Physical activity and perceived environmental attributes in a sample of Portuguese adults: Results from the Azorean Physical Activity and Health Study. Prev Med 2008, 47:83-88.

73. Shenassa ED, Liebhaber A, Ezeamama A: Perceived safety of area of residence and exercise: a pan-European study. Am J Epidemiol 2006, 163:1012-1017.

74. Sigmundova D, El Ansari W, Sigmund E: Neighbourhood environment correlates of physical activity: a study of eight Czech regional towns. Int J Environ Res Public Health 2011, 8:341-357.

75. Stafford M, Cummins S, Ellaway A, Sacker A, Wiggins RD, Macintyre S: Pathways to obesity: Identifying local, modifiable determinants of physical activity and diet. Soc Sci Med 2007, 65:1882-1897.

76. Stahl T, Rutten A, Nutbeam D, Bauman A, Kannas L, Abel T, et al: The importance of the social environment for physically active lifestyle results from an international study. Soc Sci Med 2001, 52:1-10.
77. Stronegger WJ, Titze S, Oja P: Perceived characteristics of the neighborhood and its association with physical activity behavior and self-rated health. Health Place 2010, 16:736-743.

78. Sundquist K, Eriksson U, Kawakami N, Skog L, Ohlsson H, Arvidsson D: Neighborhood walkability, physical activity, and walking behavior: the Swedish Neighborhood and Physical Activity (SNAP) study. Soc Sci Med 2011, 72:1266-1273

79. Titze S, Stronegger WJ, Janschitz S, Oja P: Environmental, social, and personal correlates of cycling for transportation in a student population. J Phys Act Health 2007, 4:66-79.

80. Titze S, Stronegger WJ, Janschitz S, Oja P: Association of builtenvironment, social-environment and personal factors with bicycling as a mode of transportation among Austrian city dwellers. Prev Med 2008, 47:252-259.

81. Toftager M, Ekholm O, Schipperijn J, Stigsdotter U, Bentsen P, Gronbaek M, et al: Distance to green space and physical activity: a danish national representative survey. J Phys Act Health 2011, 8:741-749.

82. Van Dyck D, Deforche B, Cardon G, De Bourdeaudhuij I: Neighbourhood walkability and its particular importance for adults with a preference for passive transport. Health Place 2009, 15:496-504.

83. Van Dyck D, Cardon G, Deforche B, Sallis JF, Owen N, De Bourdeaudhuij I: Neighborhood SES and walkability are related to physical activity behavior in Belgian adults. Prev Med 2010, 50(Suppl 1):S74-S79.

84. Van Dyck D, Cardon G, Deforche B, De Bourdeaudhuij I: Urban-rural differences in physical activity in Belgian adults and the importance of psychosocial factors. J Urban Health 2011, 88:154-167.

85. Van Dyck D, Cardon G, Deforche B, Giles-Corti B, Sallis JF, Owen N, et al: Environmental and psychosocial correlates of accelerometer-assessed and self-reported physical activity in Belgian adults. Int J Behav Med 2011, 8:235-245

86. Van Dyck D, Cardon G, Deforche B, Owen N, De Bourdeaudhuij I: Relationships between neighborhood walkability and adults' physical activity: How important is residential self-selection? Health Place 2011, 17:1011-1014

87. Van Dyck D, Cardon G, Deforche B, De Bourdeaudhuij I: Do adults like living in high-walkable neighborhoods? Associations of walkability parameters with neighborhood satisfaction and possible mediators. Health Place 2011, 17:971-977.

88. van Lenthe FJ, Brug J, Mackenbach JP: Neighbourhood inequalities in physical inactivity: the role of neighbourhood attractiveness, proximity to local facilities and safety in the Netherlands. Soc Sci Med 2005, 60:763-775

89. Van Tuyckom C: Macro-environmental factors associated with leisuretime physical activity: a cross-national analysis of EU countries. Scand J Public Health 2011, 39:419-426.

90. Vandenbulcke G, Thomas I, de Geus B, Degraeuwe B, Torfs R, Meeusen R, et al: Mapping bicycle use and the risk of accidents for commuters who cycle to work in Belgium. Transp Pol 2009, 16:77-87.

91. Vandenbulcke G: Cycle commuting in Belgium: spatial determinants and "re-cycling" strategies. Transp Res: Part A: Pol Practice 2011, 45:118-137.

92. Wendel-Vos GC, Schuit AJ, de Niet R, Boshuizen HC, Saris WH, Kromhout D: Factors of the physical environment associated with walking and bicycling. Med Sci Sports Exerc 2004, 36:725-730.

93. Wendel-Vos GCW, van Hooijdonk C, Uitenbroek D, Agyemang C, Lindeman EM, Droomers M: Environmental attributes related to walking and bicycling at the individual and contextual level. J Epidemio/ Community Health 2008, 62:689-694.

94. Saelens BE, Sallis JF, Black JB, Chen D: Neighborhood-based differences in physical activity: An environment scale evaluation. Am J Public Health 2003, 93:1552-1558.

95. Cerin E, Saelens BE, Sallis JF, Frank LD: Neighborhood environment walkability scale: Validity and development of a short form. Med SCi Sports Exerc 2006, 38:1682-1691.

96. Cerin E, Conway TL, Saelens BE, Frank LD, Sallis JF: Cross-validation of the factorial structure of the Neighborhood Environment Walkability Scale (NEWS) and its abbreviated form (NEWS-A). Int J Behav Nutr Phys Act 2009, 6:32.

97. de Melo LL, Menec V, Porter MM, Ready AE: Personal factors, perceived environment, and objectively measured walking in old age. J Aging Phys Act 2010, 18:280-291. 
98. Cerin E, Sit CH, Cheung MC, Ho SY, Lee LC, Chan WM: Reliable and valid NEWS for Chinese seniors: measuring perceived neighborhood attributes related to walking. Int J Behav Nutr Phys Act 2010, 7:84.

99. Reis JP, Bowles HR, Ainsworth BE, Dubose KD, Smith S, Laditka JN: Nonoccupational physical activity by degree of urbanization and U.S. geographic region. Med Sci Sports Exerc 2004, 12:2093-2098.

100. Pont K, Ziviani J, Wadley D, Bennett S, Abbott R: Environmental correlates of children's active transportation: A systematic literature review. Health Place 2009, 15:849-862.

101. Prins RG, Oenema A, van der Horst K, Brug J: Objective and perceived availability of physical activity opportunities: differences in associations with physical activity behavior among urban adolescents. Int I Behav Nutr Phys Act 2009, 6:70.

102. Gebel K, Bauman A, Owen N: Correlates of non-noncordance between perceived and objective measures of walkability. Ann Behav Med 2009, 37:228-238

103. McCormack GR, Shiell A: In search of causality: a systematic review of the relationship between the built environment and physical activity among adults. Int J Behav Nutr Phys Act 2011, 8:125.

104. Loukaitou-Sideris A, Eck JE: Crime prevention and active living. Am J Health Promot 2007, 21:380-389.

doi:10.1186/1471-2458-12-807

Cite this article as: Van Holle et al:: Relationship between the physical environment and different domains of physical activity in European adults: a systematic review. BMC Public Health 2012 12:807.

\section{Submit your next manuscript to BioMed Central and take full advantage of:}

- Convenient online submission

- Thorough peer review

- No space constraints or color figure charges

- Immediate publication on acceptance

- Inclusion in PubMed, CAS, Scopus and Google Scholar

- Research which is freely available for redistribution 